\title{
Media as Material: Information Representations as Material Foundations for Organizational Practice
}

Paul Dourish and Melissa Mazmanian

\author{
Department of Informatics \\ University of California, Irvine \\ Irvine, CA 92697-3440, USA \\ jpd@ics.uci.edu,m.mazmanian@uci.edu \\ Working Paper for the Third International Symposium on Process Organization Studies
}

Corfu, Greece, June 2011

\begin{abstract}
Through a confluence of different disciplinary interests and trajectories, questions of the materiality of digital media and information technologies have recently come into relief. There are several different strains of work under this broad umbrella and it is valuable to distinguish between the varied concerns. This paper has two objectives. First we begin by teasing apart and describing five related ways to conceptualize the materiality of digital goods. Our goal in this is to provide a typology for delineating current streams of research and language for analysis. Second, we unpack one of these conceptions in terms of socio-technical systems and organizational practices. Specifically, we analyze the role of digitization and simulation, or the materiality of digital representation, in order to shed light on how social and organizational systems respond to, create practices around, and develop delineating logics about digitally rendered data.
\end{abstract}

\section{An Anecdote}

One day, in the period when I (Dourish) was working as computer system manager for a university research center, a data tape arrived from the United States. It contained a corpus of much-anticipated research material that had been much anticipated. I mounted it in the tape drive on our DEC VAX 11/750 minicomputer, but we were unable to read it successfully. The tape drive did not register any readable data on the tape. Since tape is occasionally an unpredictable medium, I unmounted it and then tried again using the tape drive of the other VAX in the same machine room that we shared with a neighboring research group, again without success. I subsequently tried to read it on the two other tape drives in the building, attached to computers produced by other manufacturers, with no more luck. 
After consulting with some colleagues, the consensus was to take the tape to the local computing center where surely something would be able to read it. The results were frustrating (although I did get to see a whole lot of new computer systems up close). Eventually someone suggested that I take the tape to one of their long-term employees, Harry, so that he could "eyeball" it. Computer magnetic tape, like old audio recording tape, comprises nothing more than a long spool of plastic material covered in a brown magnetic oxide, so I was confused by the idea that it might reveal anything to the human eye - or to Harry's in particular - but, out of options, I did as suggested.

In his office, Harry unspooled a few feet of tape. He reached into his desk drawer and pulled out a small object that consisted of a metal ring about $4 \mathrm{~cm}$ in diameter, which held in place two thins glass sheets with a grey liquid in between. The grey liquid turned out to be iron filings in suspension. Harry stretched out the tape on a piece of blank paper, placed his device on top, and, pencil in hand, slid it slowly up and down the tape, occasionally tapping the ring gently. The iron filings began to line up in relation to the data stored on the tape. Moving the ring up and down, Harry located an empty space the inter-record marker - and made a mark on the paper below; he moved the ring up the tape to find another and made a second mark. After measuring the distance between them with a ruler, and doing a quick calculation, he looked up and said, “Ah, here's your problem. It's a 400 bpi (bits-per-inch) tape. The only drive that will read this is on the ICL [mainframe].”

He was right. We got our data.

\section{Introduction}

Information - most particularly, digital information and the processes by which it is generated, collected, managed, distributed, and employed - has come to play such a pivotal role in all aspects of Western life that many theorists have suggested that our contemporary condition be dubbed an "information society" (or similar terms such as network society and knowledge society) (Castells 1996, Webster 2006). In many of these accounts, a key feature of information is its dematerialized form. Indeed, the shift to an information society is, often, a shift from material objects to digital equivalents on 
computer screens (as in online shopping, online movie rentals, digital libraries, electronic newspapers, and digital health records, for example). Technology pundits applaud this "substitution of bits for atoms" associated with digital technologies and suggest that the 'future,' will be fueled by some vague and ideal sense of digitality. As in the words of Negroponte,

We are not waiting on any invention. It is here. It is now. It is almost genetic in its nature, in that each generation will become more digital than the preceding one. The control bits of that digital future are more than ever before in the hands of the young. Nothing could make me happier. (Negroponte, 1995, epilogue pg. 231)

However, even in this information-rich environment, the physical world persistently makes itself felt. Networks fail when undersea cables are broken and information is lost when cloud services fail. The microprocessor engineers whose work fuels the digital revolution find themselves locked in daily struggle with the limits of physical fabrication and the properties of semiconductor materials. More broadly, the information that undergirds the "information society" is encountered only ever in material form, whether that is marks on a page or magnetized segments of a spinning disk. Increasingly, social scientists have turned their attention to the intertwining of social phenomena with the material world, arguing both that the social world manifests itself in the configuration and use of physical objects and that the properties of those physical objects and the materials from which they are made - properties like durability, density, bulk, and scarcity condition the forms of social action that arise around them.

Organizational scientists (e.g. Orlikowski and Scott 2008), anthropologists (e.g. Miller 2005), sociologists (e.g. Mackenzie 2009), STS scholars (e.g. Suchman, 2007) and feminist scholars (e.g. Barad, 2003) have begun to unpack the importance of the specific material configurations of our informated world.

These writers have focused on the material aspects of social life. Taking information as itself a social phenomenon - social in both its origins and its implications - we are similarly concerned with the materiality of information. Our goal here is to sketch a framework that begins to illuminate the consequences of the particular and various materialities of information as they arise in organizational, social, and cultural practice. 
When we focus on information as a material object - either as it is instantiated in information systems of all sorts, or as it manifests itself in the representational systems that contribute to the shape and character of life in information society - then we begin to recognize the historical particularities, cultural specificities, and political consequences of information work. In particular, this perspective draws our attention to the specific representational practices associated with contemporary information science.

In talking of materiality here, we want to go beyond the brute fact of material forms. That is, what is of interest to us is not simply the fact that apparently abstract and ineffable digital "stuff" actually takes material form; rather, we want to understand the particular material properties of these forms and their consequences for how people encounter, use, and transform them. Particular material properties might include mutability, persistence, robustness, spatiality, size, durability, flexibility, and mobility. Information practice arises in conversation with these specific properties of information and its material forms. In speaking of materiality, rather than simply of material-ness, we have in mind these specific considerations.

As an illustrative example, consider the case raised by Edwards (2011) in his study of climate science, where he notes the problems faced by the U.S. National Weather Records Center in storing meteorological data on punched cards in the early 1960's. Their concern was not that they had more data that they might be able to process; rather, it was that they might have more data than their building could physically support. One gigabyte of data on punched cards weighs over 35 tons. It is not simply that that is a lot, although it is. The specific material instantiations of the data have implications for where it can be stored (and therefore for the kinds of institutions that can afford to house it), for how quickly it can be moved from place to place, for how easily elements can be accessed, and so on. In turn, this shapes our ideas about the kinds of questions that can be asked of data, the sorts of information we have available to us, and what we assume is worth collecting. Transformations in storage media play out as reconsiderations not simply of the availability of information, but also of the institutional auspices under which it can be collected and managed, its lifetime, the temporalities of access, its 
resistance to change, and even what we think of as being practical as a data set in the first place.

In what follows we begin by setting out a range of perspectives of the materiality of information. The landscape is vast, and it is not our goal to attempt to explore it all here; instead, by quickly sketching a set of related research topics, we aim to provide a language for discourse that facilitates the emerging and overlapping interests arising in various fields. We then attempt to identify a smaller (although still huge) area that will command our particular attention, the materiality of digital representations. We present some initial grounding for this work, but our preliminary exploration here is conducted largely through an examination of two particular cases - the case of amateur digital photography, and the case of nuclear weapons testing. We close with some broad remarks concerning potential future directions for this stream of work.

\section{Aspects of the Materiality of Information}

What do we mean by the materiality of information? Several different possibilities present themselves, and all are relevant. For practical purposes here, we begin by presenting five conceptualizations of the materiality of information in the context of digital technology.

The first could broadly be described as the material culture of digital goods. Anthropologists have, for several decades, have investigated the ways that physical objects carry symbolic value and do important cultural work; examples include studies of homes (e.g. Cledaad 1999), cars (e.g. Miller 2001), and the Sony Walkman (Bull 2000). Digital goods - as icons of modernity, as fashion statements, as affiliative objects, and more - clearly play similar roles as elements of material culture. Into this category we place examinations of the cultural currency of particular digital products such as iPhones, netbooks, or the Linux operating system. Digital goods can have symbolic meaning in terms of personal histories and local significance, but more broadly - as possessions, as objects of aspiration, as demonstrations of status, as elements of interpersonal and as projections of self-identity - digital goods in and of themselves play a broader cultural role. They make a statement and they carry symbolic weight, particularly in the transition 
from non-digital to digital ways of working. The materiality of digital technology, then, encompasses the study of digital technologies from the perspective of material culture as one component.

The second aspect of materiality in the realm of digital technologies might be dubbed the transformative materiality of digital networks. Information technologies of various sorts are increasingly woven into the fabric of everyday space, from home gateways to rural cellular telephone coverage, and these condition our experience of those spaces. Increasingly, cultural geographers and urban theorists recognize the role that information and information technologies play in the encounter with space (e.g. Kitchen and Dodge 2011, Graham and Marvin 2001). The availability of infrastructures organizes and contextualizes human action and the various meanings that space can have, both in the small (e.g. cell phone dead zones, wifi-enabled cafes, broadband-connected homes) and in the large (e.g. cities differentiated by their data infrastructure, concentrations of manufacturing industry, regions marked by different approaches to regulation of digital services or the allocation of wireless spectrum.)

In this second category we include work that concerns the physical properties of digital technologies considered as aspects of infrastructure and the built environment. So, for example, a materialist perspective on the emergence of novel forms of virtual organization in light of the spread of high-speed networks might reflect this perspective, focusing on the mutual constitution of organizational practice and technologies of communication, from open source communities to e-government to distributed teams. Similarly, research into the cultural geography of information technologies, from the spatial politics of digital urbanism to the reshaping of public space through WiFi and WiMax networks, reflects this second approach.

The third conception concerns the material conditions of information technology production, or a Marxian account of the economic conditions favored by the speed, ubiquity, and manipulability of information rendered into digital forms. Whenever we talk about digital information, we also talk, if implicitly, of a host of other elements critical to making it work: server farms located on costly real estate and with massive power costs; labor, both skilled and unskilled, to build technologies, encode information, 
maintain infrastructures and facilities and deal with increasing amounts of toxic e-waste (e.g. Pellow and Park 2002); corporate and governmental alliances and partnerships; systems of legislation, regulation, and compliance; and national and supra-national regimes of governance, from telecommunications deregulation and "net neutrality" to NAFTA, GATT and WIPO. Each of these elements involves embedded power relations that reflect resource streams, capitalist production and consumption logics, and hidden labor.

Notwithstanding the image of entrepreneurs in Silicon Valley garages and billion-dollar businesses launched from Harvard dorm rooms, building and deploying digital technologies and information systems typically requires significant capital resources. (A garage, after all, costs a fair amount in Silicon Valley, and so does a Harvard education.) Talking of the materiality of contemporary information experiences, then, most certainly includes the question of the power and resources needed to bring those systems and infrastructures into being, and the ways in which information systems themselves must reproduce the conditions of their own production (Althusser 2001).

The fourth topic is the consequential materiality of information metaphors. Information has become one of the universal metaphors of contemporary life and this metaphor implies an informational approach to seeing and understanding the world that diminishes some forms of knowledge and authorizes others. Certainly, we see this in formalized domains, such as genomics and bioinformatics that depend on an "informational" reading of biological processes. Such activity reshapes the domain of biology by refocusing attention and activity of those engaged in studying it and presenting this domain to others. It redirects funding dollars, reorganizes the corporate competitive landscape, and reshapes disciplinary structures.

Further, it amplifies the metaphorical claims of information and information science, which have been an explicit object of academic attention ever since Warren Weaver's pioneering commentary on Shannon's mathematical theory of communication set out an informational reading of human and social life (Shannon and Weaver 1949, Day 2008). Directing attention through informational metaphors is pervasive in everyday settings as well, where information flows, models of data processing, and computational command- 
and-control serve as cultural logics for understanding and narrating the world around us, whether psychological experience (how we "store" and "process" events), commercial activity ("viral" advertising draws more on the logic of computer viruses than it does on biological ones), or bedsprings ("sense-and-respond coils," in the parlance of one American television ad that occasionally graces our screens). As is often the case with such key metaphors, they begin to have material consequences as those elements of the world that do not easily fit into the metaphor (emotion, for instance) are either reframed or become invisible in public discourse. "Information" becomes the universal solvent for both what the world is and how it can be framed.

The fifth construal of the materiality of information is a topic that we describe as the materiality of information representation. The central concern here is the representational consequences of the materiality of digital forms. The particular forms that information takes - graphical and lexical expressions, columns of numbers, or records in a relational database - shape the questions that can be easily asked of it, the kinds of manipulations and analyses it supports, and how it can be used to understand the world. So, we are interested in examining the material forms in which digital data is represented and how these forms influence interpretations and lines of action - from the formal syntax of XML to the organizational schemes of relational databases and the abstractions of 1 and 0 over a substrate of continual voltage - and their consequences for particular kinds of representational practice. The ways in which information can be interpreted, negotiated, manipulated and understood to represent then carry implications for organizational processes and social practice. Such materialities influence how data is taken up by different constituents, used to further social and political aims, and employed as an object in games of persuasion, negotiation or identity making.

Each of these five accounts of information materiality - the materialities of information goods, of information infrastructures, of information production, of information metaphors and of information representations - frames important considerations. The perspectives are united by the recognition that the ineffable "stuff" of digital abstractions is encountered only ever in material forms, and the nature of those forms has consequences for how information practice develops. Given the intense development of 
information models as a basic of contemporary life - in state bureaucracies, in organizations, in social life, and in cultural practice - these material considerations play potentially powerful roles in everyday experience.

What's more, it is clear that, although we can identify these strands (and others) within a broad study of the materiality of information, they cannot be separated. They provide analytic distinctions, but the empirical phenomena are woven together. The robustness of representations to different forms of manipulation helps sustain the metaphors. The material conditions of information technology production incorporate and shape the networked infrastructures and spatial arrangements of digital urbanism. The prevalence of digital goods shapes the power and reach of metaphors. As a framework, then, this provides only a broad account of the different elements that might be at work in a materiality of information. And, while each construal would support detailed investigation, it is the fifth - the materiality of information representations - that we will particularly examine for the rest of this paper.

\section{The Materiality of Digital Representations}

Our concern with the materiality of digital representations springs from similar considerations in the history of representational practice more broadly.

Ong (1988), for example, examines the relationship between orality and literacy and argues that they represent not just different forms of expression but different worldviews. From the perspective of a literate culture, we might marvel at the acts of memory involved in being able to remember and recite long poems or stories accurately; however, accuracy in the sense of word-for-word reproduction is not a consideration in oral societies since there is no written record against which something can be compared. The very idea of exact reproduction in this sense is itself an artifact or consequence of literacy. The effectiveness of a performance as a primary criterion is displaced by (or at least accompanied by) a focus on the accuracy of reproduction. Ingold (2007) argues that the experience of linguistic linearity is similarly a consequence of written notations for language. More broadly, our experience of an external representation for linguistic 
utterance itself shapes our idea of what language can be, and in particular, is critical to the idea of information that can be separated from verbal performance.

Goody (1977) sets out the entwined history of western knowledge practices and its representational forms, arguing that different representational forms provide different structures for encountering, organizing, and knowing the world. Lists, hierarchies, and tables provide different structures for classifying and understanding the world, and their development as representational strategies can be seen to be harnessed to the development of the different modes of knowledge production associated with them - with classification and ordering, with generalization and grouping, and with relationality and comparison. Goody argues that what can be set out on the page - with the representational capacities of different lexical devices - shapes what can be known.

Writing from a very different perspective, Green and Petre (1996) make some similar observations in the area of computer programming. Their studies of students learning to program computers suggested that the types of problems that they encounter are coordinated with the lexical properties of the programming languages they are learning. In short, different programming languages - not just conceptually, but lexically, as words on paper or letters on the screen - have different properties that make them subject to different kinds of problems. Green and Petre unpacked what they called the "cognitive dimensions" of programming languages as notations, including consistency, progressive evaluation (how easy it is to test a partial solution), and viscosity (a measure of how easily change can be introduced).

Ong and Goody, then, start to uncover the ways in which representational forms and knowledge practices are coupled. Green and Petre provide a bridge to the domain of digital information by focusing on the notational aspects of computer systems. However, their analysis focuses largely on the aspects of notations that are immediately visible to people as an aspect of interaction with computers, not to the "internal" representations of information systems.

Manovich's (2002) analysis of new media provides a stronger connection to the broader world of digital representation. Manovich places new media arts in a broader historical 
context, arguing that the database is the major cultural form of the $21^{\text {st }}$ century in much the same way as the novel was for the $19^{\text {th }}$ and the film for the $20^{\text {th }}$. In particular, he draws attention to the increasing primacy of relationality over narrative sequence. While retaining the visual and temporal aspects of film, the modality of hypertext or of computer games eschews its lineary modality for the modality of the database, in which objects are linked together but their assembly into a narrative experience is in the hands of the audience. What Manovich's argument provides for us here is a connection between digital practice and the broader arguments raised by people like Goody in the context of historical knowledge production; that is, he begins to outline how the representational properties associated with digital media affect aspects of the interactional experience and, in turn, how we encounter the world through the computer. In particular, the centrality of non-linear relationality as the primary mode of database-driven interaction has broader implications for accounts of both the natural and the social world that are shaped by computer systems and ways in which information is received, organized, and interpreted via interaction with database schemes and logics.

Curry (1998) provides many examples of this encounter with the world through the lens of the database in his account of the rise of geographical information systems. As a simple example, for instance, consider the development of geodemographic marketing. Based on the intuitive premise that "you are where you live," geodemographic marketing comprises, first, the development of a series of lifestyle profiles indexed by geographical region (in the United States, typically ZIP codes), and, second, targeted marketing based on particular localities and their specific properties. People working in the field readily acknowledge that these sorts of demographic profiles are, at best, rough and ready accounts, and that ZIP codes are scarcely the best tool for delineating regional clusters. However, when these sorts of profiles are used to target service provision, to support decisions about locating public services or commercial outlets, or to shape zoning decisions, then they become self-fulfilling prophecies. In this way, a variety of virtual boundaries that existed purely internally to the information system - both the geographical boundaries of ZIP codes and the social boundaries of market segments - are reinforced and begin to take on a life of their own. 
In his account of what he calls "virtualism", Miller $(1998 ; 2005)$ has noted that representational models and reductive accounts of social life have a habit of migrating to centers of power where they can become tools of governance, reinforcing (and justifying) their own limits. His examples include the rules of neoclassical economics which, once they become the primary operative tools of organizations such as the World Bank and the International Monetary Fund, become prescriptive models of allowable economic process (see also Mackenzie 2006); or the forms of audit rationality that begin as descriptive accounts but rapidly become tools to manage the provision of state services. Curry's examples, amongst others, highlight the role that information representations play within this pattern, since the models at work are ones that are often embedded in and shaped by computational tools and datasets.

In computer science research, many people have recently become interested in what is termed "computational thinking" (Wing 2006). As a broad manifesto, computational thinking argues that the basic elements of computational systems - structured data and algorithms - are now so central to everyday life that an understanding of their fundamentals is as important to contemporary education as an understanding of the fundamentals of mathematics, logic, and symbolic reason. The computational thinking agenda then is largely an educational one, but also one that places computer science and information science at the center of a range of scientific and policy agendas.

This view of computational thinking, though, is one that is largely dehistoricized and dematerialized. It is a vision that can be complicated by the idea that the computational thinking with which we are familiar is one particular computational thinking, one that has arisen in parallel with particular kinds of computer systems, particular kinds of software systems, and so particular kinds of representational and modeling practices. It is one amongst a possible range of computational thinkings. Elsewhere, we argue that it is important to recognize and to challenge the dominance of specific modes of knowledge practice embedded in computational thinking, but recognizing that there might be other ways of thinking computationally than those espoused by current computer science or information science research (Dourish 2011). Again, we hope that a focus on the materiality of information can open up these lines of inquiry. 
In order to make these concerns more concrete, we turn now to two examples that illustrate the complexity of practical encounters with the materiality of information.

\section{Examples: Materiality in Focus}

In this section, we call upon two examples from current research to demonstrate this approach to analyzing the intersection of the representations of digital information (and re-representations of data into the digital realm) and organizational practices. The first concerns the impact of digital photography on the organization of groups concerned with artistic practice; the second focuses on the advent of digital simulation as the primary site of nuclear weapons testing.

\section{Digital Photography}

Our first example focuses on the practices of voluntary organizations organized around artistic leisure pursuits, specifically camera clubs (Grinter 2005). Photography denotes more than simply a technical process for capturing images; it denotes a system (or series of systems) of visual culture and practice. What makes a good photograph or a bad one, what distinguishes a casual snapshot from an artistic piece, the degrees of artifice and manipulation expected, and the contexts of production all reflect a series of cultural expectations about what the domain of "photography" comprises, which are grounded in but not limited by the material conditions of photographic production and reproduction. X-rays and satellite images are rarely thought of as examples of "photography," for example while the emergence of cellphone cameras created the opportunities for new forms of casual and informal visual practice to emerge (only in the context of these devices did it come to make sense to regular take and distribute photographs of food, of your new haircut, or of a pair of jeans you're trying on).

On the one hand, the physical materiality of digital photography, in comparison to film photography, allows us to rethink what is "worthy" of photographic documentation - so, images are available immediately rather than after a delay for processing; images can be taken as experiments and easily deleted without wasting expensive film; images can be shared immediately, either around the camera or across networks; image libraries of tens or hundreds of thousands of photographs can be stored and accessed with relative ease. 
On the other hand, it needs to be incorporated into an existing set of conventions, understandings, and procedures that surround "photography" as a practice.

The struggles that amateur photography clubs faced at the advent of consumer digital photography, as discussed by Grinter (2005), provide an interesting example of digital materiality and its entwinings with practice. At the time when Grinter's study was carried out, digital photography was becoming sufficiently popular within amateur enthusiast circles that the camera clubs needed to be able to respond to the way that the new technology questioned established community practices. These arose in particular over the way that competition categories had arisen around aspects of photographic practice, and the troublesome relationship between digital and print photography's materialities. We will focus in particular on two concerns.

The first concerns the process of photo print production. One of the categories for photographic competitions concerned maker-made prints. To be eligible for this category, photographic prints had to have been produced by the photographers themselves, rather than having been produced by commercial print processors. For the photographers, whose shared values express the strong belief that the artistry of photographic production happens at least as much in the darkroom as it does behind the viewfinder, the process of print production is critically important. However, the question of what it means to "make" a print - to have control over this process, and to possess the means to make it is thrown into question by digital photography. Must one personally own the printer, for instance? If one makes a print on a printer at a commercial outlet, is that equivalent to personal production or to a commercial service? At which point in the process must the maker's hand be involved - pressing the print button itself? Where the production of film photography prints inherently involves an engagement with materials - development chemicals, fixer, papers, and so on - the same scope of artistic production disappears in the digital process, so that a distinction between self-made and commercially-produced prints no longer makes sense. The categories by which images were judged, tied as it was to a particular material experience, had ceased to be effective as the materiality changed.

The second concern that the amateur photographers found themselves dealing with illustrates this even more starkly. Again, the artistry and creativity of darkroom practice 
is the practice on which things turn. This is a form of post-processing of images. Essentially, while the act of taking the photograph itself (exposing the film) constitutes a critical act in the production of an image, the actual image that results is not fixed at that moment; it is in the darkroom that specific images are produced. Manipulating the chemical process of developing in image provides many opportunities for creative engagement; cropping and photographic manipulation provides more; and some photographers might actually physically manipulate an emerging image to produce other artistic effects (e.g. through deliberate smearing or cutting.)

Digital photography is also, of course, subject to many forms of post-processing, but the material constitution of digital images allows for forms of manipulation quite different from those that film photography affords. Digital tools such as Adobe Photoshop can transform an image dramatically, introducing elements that were not present when the image was taking, or removing or reconfiguring elements that were. This presents a much more complicated set of considerations to amateur photographers. Competition categories can depend upon (amongst the groups that Grinter studied, for instance, "nature" shots are required to have no visual indication of human activity: no fence posts, no footpaths, and no mowed lawns, for example), but the availability of digital manipulations of the radical sort allowed by Photoshop threaten the effectiveness of these categorical distinctions. At the same time, clearly post-processing cannot be outlawed; indeed, it is celebrated as part of the work of photography.

So the problem that the photographers found themselves grappling with was not simply that the digital material is different from the film material; it was, rather, that the nature of these different materialities potentially required a wholesale revision of the way that the practice of image-making was imagined as a community process. The stuff of images was not simply bound up with a process of image making, although that is clearly the case; rather, the materiality was woven also into the way that the community conceived of itself, understood its own structure, celebrated and valued particular kinds of craft, interpreted images, and explored the creativity associated with the material constraints of its foundational technologies. 
What is especially interesting here is that the representational forms associated with digital and film photography are not directly substitutable in terms of the sorts of practice that they enable. While a digital print may be nearly indistinguishable from a traditional film print, at least to the untrained eye, as records or outcomes of a history of practice, they are quite different sorts of objects. Their material natures carry different potentialities and different constraints.

\section{Nuclear Weapons Testing}

Our second example also revolves around a radical change in material practice, in this case in the area of nuclear weapons testing (Gusterson 1996; 2001; 2008). With the banning of nuclear testing emerged new forms of data about nuclear warheads and restrictions on how old data could be put into practice. As the cold war fell and test bans became politically appealing, the government poured billions of dollars into advanced simulation technologies for the labs once built to blow things up. The purported goal of introducing such technologies was to keep the current arsenal intact (pinpointing degradation and selectively fixing warheads) while maintaining scientific innovation and excitement in a field that could quite quickly need to be revitalized become crucial for national security.

However, within entrenched organizational logics and bureaucratic structures, Gusterson traces how this transition has been fraught with internal fissuring. The scientists themselves must figure out - as factions and as a discipline - how to make sense of the data emerging from simulation technologies purported to enable greater knowledge of nuclear warheads. The activities involved with determining and assessing understanding of the data, interpretation of what these data imply, and orientation toward future possibilities, requires a faith in a simulated modeling that goes against traditional logics associated with "blowing things up." Nuclear physicists were accustomed to testing assumptions in grand fashion and such practices were key to the body of shared knowledge and professional identity within the discipline. New knowledge (at both the individual and disciplinary levels) about how any model of warhead will work, and calculations about reliability and degradation, are the result of complex simulations. Yet, the implied power, danger, unpredictability, and fear of the weapon remains. The 
scientists themselves are caught between an inability to feel they can 'know,' in any definitive sense, what they are tasked with stewarding. Gusterson's work suggests the crushing uncertainty that can emerge when potent information becomes represented digitally. Further, he traces how this uncertainty can create a clashing of discursive logics at multiple levels simultaneously (the individual, within institution, within discipline, across a political and international landscape).

Without a direct mapping to empirical results that all can see and rally around there is a greater ambiguity about what the simulations mean and how such meaning is calculated. As the simulation regime continues, the disjuncture between physical weapons and their simulations grow. Simulations of nuclear warheads become simulacra in Baudrillard's sense - simulations of objects (in this case, explosions) that never themselves existed. The materiality of the simulation displaces that of the weapon. One consequence of this displacement is the fact that the development of weapons testing regimes (and hence weapons design) now becomes harnessed to a radically different technology, that of the digital simulation, both in the form of the computer system and in the form of the mathematical models that these simulations implement.

New forms of supercomputer, new technological capacities, and new system architectures do not simply make the process of simulation faster; they open up new avenues of investigation by bringing new capabilities within the realm of the thinkable and the doable, much as Fujimura (1987) has noted in her work on cancer research. The technologies of "simulation," then, become the technologies of possibility for the physical processes that they are meant to simulate, and the architectures and capacities of those technologies shape the design and research processes themselves. Edwards (2011) has noted this relationship at work in climate modeling, which rivals nuclear testing as the primary consumer of advanced supercomputer technologies; indeed, the very kinds of climate data that we collect are shaped, in part, by what our computer models can process.

Recognizing the inherent tie between representation of information and possibility for action, Gusterson outlines four "plateaus of calculation" that are accompanied by alternating narratives of the future and parties invested in bringing it to the fore as a key 
determinant in future lines of activity: Geopolitical, strategic, enviro-political, and technoscientific. Each of these lines of thought, relevant players, implied variables of importance, and anticipatory futures, is being established and asserted in the inescapable context of purely simulated data. Positions are taken, rallied around, and negotiated in terms of how one interprets the role and possibilities of that data. The data itself is understood in dramatically different terms as a discipline formed around nuclear testing is now forced to make sense of itself solely within the purview of the hyper-real.

In other words, this world of simulation without empiricism, that emerged from a logic of testing and visceral experiential knowledge, is stymied by competing claims as to the appropriate role of simulation based knowledge in stewarding current warheads and building new ones. The status and meaning of information is up for grabs even among the small group of expert scientists who control and create it. This situation goes far beyond a view of science as "socially constructed" as even those invested in proving their findings cannot find grounding or shared logics to establish the meaning and validity of this new form of data. As Gusterson asserts, "in the situation under discussion here, there is a sort of surplus of ambiguity created by the unique features of contemporary nuclear weapons science so that in this case the available evidence is not just constructed, but hyperconstructed." (Gusterson 2008:559).

Some scientists in the testing laboratories assert that simulated data is a frightening, if not disastrous, method for creating future designs (even those modified from older "pedigreed" designs). Without the experiential feel for how explosions happen, and the tacit knowledge of doing that is quickly retiring out of the testing facilities, the inability to prove oneself wrong is potentially dangerous and arrogant. Others feel that movement toward simulation in nuclear design is both inevitable and beneficial, arguing that through deeper insight into how nuclear fusion works we can build more reliable and tailored warheads in a constrained political and empirical environment. Is simulated nuclear data the "grand challenge" or road to disaster? According to Gusterson, the hyperconstructed form of the data makes it difficult for these debates to settle, for dominate logics to take hold, even within the immediate scientific community of those 
responsible for shepherding our nuclear arsenal no less within the broader geo-political ecology of power.

What is of particular importance here is the role of digital simulation as an entity in its own right. The information as represented - represented as misaligned objects, implied insights, and orienting maps - becomes material in substantive and unexpected ways. The limitations of testing regimes are the limitations of technological simulation. Information technology plays more than an enabling role here, then. As simulation technologies and the platforms on which they run evolve, new forms of weapons and new ideas about weapons become possible, because the weapons and their capabilities as we know them are fundamentally entwined with the material limitations of simulation technology.

\section{Conclusion}

Much of the rhetoric that surrounds information technologies and new media focuses on the apparently immaterial nature of digital representations (Poster 2006). Digital information, though, is encountered only ever in material forms. Just as social scientists have increasingly recognized the significance of materality in social and cultural practice, so too has recent attention turned to the materialites at work in information practice (e.g. Kirschenbaum 2008, Montford and Bogost 2009, Blanchette 2011). Our current work represents a contribution to this discussion with a particular focus on the materialities of digital representations and their consequences.

In particular, we would like to place contemporary digital practice within a historical pattern of entwined development of representational forms and knowledge practice, and so to examine the representational contexts and consequences of digital information systems.

We have used the brief examples of digital photography and nuclear weapons testing to ground our discussion. These examples are evocative demonstrations of the complex interplay between organizational and social processes and the materiality of representational forms enabled by information technologies. In these vignettes, representational forms of data and response characteristics of social systems co-mingle. 
Together, they shape organizational practices and concomitant logics of legitimacy. We find it evocative to place digital photography alongside nuclear testing as these two narratives suggest how shifts in digital representation of information can inspire fear, aggression and insecurity in dramatically different scenarios. Hobbyists, who enjoy photography as an outlet for artistic expression, individual identity, and social interaction were threatened, upset, and unnerved by digital photography in a manner that parallels that of scientists tasked with some of the most politically sensitive and hazardous questions of our age.

In recent years, organizational, anthropological, and digital media scholars have begun to explore, tease apart, and engage in relatively isolated discussions about the materialist foundations of digital practice (Manovich 2002, Horst and Miller 2006, Orlikowski 2007, 2008, Montford and Bogost 2009, Leonardi and Barley 2008, 2010, Blanchette 2011). As we have noted, different forms of materiality are on display here.

Our focus on material representation of digital goods highlights an underexplored facet of analysis in socio-material studies. Focusing on the interrelationships between digital forms, epistemology, and social process provides a nuanced and productive lens for exploring the ways in which people appropriate digital forms and digital forms shape social environments. We look to the emerging area of Software Studies (Fuller 2008) for examples of how scholars of different disciplinary stripes have recently taken steps in this direction. Borrowing approaches and techniques from other areas of media studies in the attempt to understand the specific conditions of new media production and use, Software Studies has begun to theorize the importance of digital forms in shaping thought and practice. We hope to further build on this perspective by emphasizing how studies of the materiality of information and information technologies need to push beyond digital as metaphor and relational logic and be strongly engaged with the specifics about the different properties, representations, and materialites of digitized information itself. That is, given that our interest in materiality is in material properties and their consequences, it is important that digital technologies are not understood merely metaphorically or analogously with media, but that their specific materialities - and the entangling of those materialities with particular forms of technological practice - must be at the center of any 
investigation. At the same time, in contrast to the Platform Studies model proposed by Montford and Bogost (2009), we argue for an examination of the power and consequences of the abstractions of software systems as tools for imagining, and operating upon, the social world.

In sum, this paper offers three contributions to the broad and burgeoning research stream on the materiality of information. First, by delineating how different strands of digital materiality can be understood and analyzed, this paper aims to provide a foundation for developing shared understanding about how we, as an academic community, can productively engage material studies in the realm of information technologies, technological infrastructure, and information metaphors. Second, by tracing the history of representational practices we highlight the fundamentally human experience of information and information processing in how the limited capacity of the brain understands and orients to the world. Third, by exploring two case studies of how shifts in representations of information into a digital realm affect social dynamics and discursive logics we hope to set the stage for future organizational research that takes data representation seriously as an object of analysis.

\section{Acknowledgments}

We owe considerable intellectual debts to many people whose provocations and inspirations shaped our thinking on these topics, including Geof Bowker, Wanda Orlikowski, Simon Penny, and Brian Cantwell Smith. We are grateful to Ken Cameron, Marisa Cohn, Ellie Harmon and Silvia Lindtner for early feedback on these ideas. Our work has been supported in part by the National Science Foundation through awards 1025761 and 0968608.

\section{References}

Althusser, L. 2001. Ideology and Ideological State Apparatuses. In Lenin and Philosophy and Other Essays. Monthly Review Press.

Barad, K. 2003. Posthumanist Performativity: Toward an Understanding of How Matter Comes to Matter. Signs, 28(3), 801-831. 
Blanchette, J.-F. 2011. A Material History of Bits. Journal of the American Society for Information Science and Technology, 62(6), 1024-1057.

Bull, M. 2000. Sounding Out the City. Oxford: Berg.

Castells, M. 1996. The Rise of The Network Society. Oxford: Blackwell.

Cleraad, I. (Ed). 1999. At Home: An Anthropology of Domestic Space. Syracuse, NY: Syracuse University Press.

Curry, M. 1998. Digital Places: Living with Geographical Information Systems. London: Routledge.

Day, R. 2008. The Modern Invention of Information: Discourse, History, Power. Southern Illinois University Press.

Dourish, P. 2011. The View from Arnhem Land in Australia's Remote North: "Computational Thinking" and the Postcolonial in the Teaching from Country Program. Learning Communities: The International Journal of Learning in Social Contexts.

Edwards, P. 2011. A Vast Machine: Computer Models, Climate Data, and the Politics of Global Warming. Cambridge, MA: MIT Press.

Fujimura, J. 1987. Constructing 'Do-Able' Problems in Cancer Research: Articulating

Alignment. Social Studies of Science, 17(2), 257-293.

Fuller, M. 2008. Software Studies: A Lexicon. Cambridge, MA: MIT Press.

Goody, J. 1977. The Domestication of the Savage Mind. Cambridge, UK: Cambridge University Press.

Graham S. and Marvin S. 2001. Splintering Urbanism: Networked Infrastructures, Technological Mobilities, and the Urban Condition. London: Routledge.

Green, T. and Petre, M. 1996. Usability analysis of visual programming environments: A 'cognitive dimensions' framework. Journal of Visual Languages and Computing, 7, 131-174.

Grinter, R. 2005. Words About Images: Coordinating Community in Amateur Photography. Computer-Supported Cooperative Work, 14, 161-188. 
Gusterson, H. 1996. Nuclear Rites: A Weapons Laboratory at the End of the Cold War. Berkeley, CA: University of California Press.

Gusterson, H. 2001. The Virtual Nuclear Weapons Laboratory in the New World Order. American Ethnologist, 28(2), 417-437.

Gusterson, H. 2008. Nuclear Futures: Anticipating Knowledge, Expert Judgment and the Lack that cannot be filled. Science and Public Policy, 35(8), 551-560.

Horst, H. and Miller, D. 2006. The Cell Phone: An Anthropology of Communication. Oxford:

Berg

Ingold, T. 2007. Lines: A Brief History. London: Routledge.

Kirschenbaum, M. 2008. Mechanisms: New Media and the Forensic Imagination. Cambridge, MA: MIT Press.

Kitchen, R. and Dodge, M. 2011. Code/Space: Software and Everyday Life. Cambridge, MA: MIT Press.

Leonardi, P. and Barley, S. 2008. Materiality and Change: Challenges to building better theory about technology and organizing. Information and Organization, 18: 159-176

Leonardi, P. and Barley, S. 2010. What's Under Construction Here? Social Action, Materiality, and Power in Constructivist Studies of Technology and Organizing. Academy of Management Annals, 4(1): 1-51.

Mackenzie, D. 2006. An Engine Not A Camera: How Financial Models Shape Markets. Cambridge, MA: MIT Press.

Mackenzie, D. 2009. Material Markets: How Economic Agents Are Constructed. Oxford: Oxford University Press.

Manovich, L. 2002. The Language of New Media. Cambridge: MIT Press.

Montford, N. and Bogost, I. 2009. Racing the Beam: The Atari Video Computer System. Cambridge, MA: MIT Press.

Miller, D. 1998. A Theory of Virtualism. In Virtualism: a new political economy (eds) J. Carrier \& D. Miller, 187-215. Oxford: Berg. 
Miller, D. (Ed) 2001. Car Cultures. Oxford: Berg.

Miller, D. 2003. The Virtual Moment. Journal of the Royal Anthropological Institute, 9, 57-75.

Miller, D. (Ed.) (2005). Materiality. Durham, NC: Duke University Press.

Negroponte, N. 1995. Being Digital. New York: Knopf.

Ong, W. 1988. Orality and Literacy: The Technologizing of the Word. London: Routledge.

Orlikowski, W. Sociomaterial Practices: Exploring Technology at Work. Organization Studies, 28: $1435-1448$.

Orlikowski, W. and Scott, S. 2008. Sociomateriality: Challenging the Separation of Technology, Work and Organization. The Academy of Management Annals, 2(1): 433-474.

Pellow, D. and Park, L. 2002. The Silicon Valley of Dreams: Environmental Injustice, Immigrant Workers, and the High-Tech Global Economy. New York, NY: NYU Press.

Poster, M. 2006. Information Please: Culture and Politics in the Age of Digital Machines.

Durham, NC: Duke University Press.

Shannon, C. and Weaver, W. 1949. The Mathematical Theory of Communication. Urbana, IL:

University of Illinois Press.

Suchman, L. 2007. Human-Machine Reconfigurations: Plans and Situated Actions, $2^{\text {nd }}$ ed. New York, NY: Cambridge University Press

Webster, F. 2006. Theories of the Information Society (Third Edition). London: Routledge.

Wing, J. 2006. Computational Thinking. Communications of the ACM, 49(3), 33-35. 